\title{
Ecological Compensation Mechanism of Ambient Air Quality: A Case Study of Hubei Province, China
}

\author{
Ming Zhong* and Long Wang(**)† \\ *Academic Affairs Office, Wuhan University of Technology, Wuhan, 430070, China \\ **School of Safety Science and Emergency Management, Wuhan University of Technology, Wuhan 430070, China \\ †Corresponding author: Long Wang; zmwl@whut.edu.cn
}

Nat. Env. \& Poll. Tech.

Website: www.neptjournal.com

Received: 20-02-2020

Accepted: 15-04-2020

Key Words:

Ambient air quality;

Ecological compensation;

Compensation mechanism

\begin{abstract}
Given the increase in energy consumption and the advancement of urbanization, the expected level for the prevention and control of air pollution has not been achieved, and urban air quality has deteriorated significantly. Environmental air ecological compensation has become an important method to control air pollution to realize sustainable economic and societal development. The object, method, and standard for compensation were discussed based on the case study of the environmental air ecological compensation mechanism in the Hubei Province of China. Results show that the compensation mechanism solves the negative externality of the environment caused by the fuzzy air property rights to a certain extent. Besides, the mechanism addresses the dilemma caused by the fragmented management of the local government to the collective action and promotes the transformation from the traditional pollution control mode of the regulated enterprises to the governance mode to strengthen government regulation.
\end{abstract}

\section{INTRODUCTION}

Environmental air has the characteristics of public goods, and its property rights cannot be defined. The strong fluidity of air expands the external spill over range of pollution, often across multiple administrative areas. Changes in air pollution in different cities in a region show significant synchronicity, and severe pollution weather usually occurs successively in one day. At the same time, the improvement in air quality due to the protection of air by a local government has a strong spill over effect, providing incentives for other governments to free-ride (Mao et al. 2020). Given the cross-regional nature of air pollution, a single local government may have difficulty implementing effective measures to control air pollution, which requires all governments within the scope of pollution to take collective actions and cooperate to control air pollution. However, an interest game between local governments exists under the externality of air pollution and governance and the principle of environmental protection localization. Every rational local government tends to take inaction or passive governance, and collaborative governance encounters a situation in which two local governments might not cooperate, although collaborative governance will be of their mutual interests (Wang 2014). Therefore, air pollution prevention and control strategy should be formulated. The institutional design, organizational function, and implementation of cross-regional governance should be innovated. Also, the compensation mechanism of interest driving and interest coordination of cross-regional governance of air pollution should be improved. Governments that contribute to the protection of air should be compensated and governments with the free-rider problem and passive governance need to be punished. Therefore, local governments are encouraged to take responsibility for protecting their air ecological environment and actively control air pollution.

Ecological compensation is a kind of institutional arrangement that considers the law as the premise, and market, economy, and policy as the means to promote the occurrence of compensation activities, coordinate people's interests, and mobilize and motivate people to protect the ecological environment actively (Yu et al. 2016). In this study, the ecological compensation of ambient air quality is defined as an institutional arrangement to regulate the interest relationship of various interested subjects of an air ecological environment by using the market, economy, and policy to reduce air pollution and protect the air ecological environment. This process includes not only charging the air polluter but also compensating the victims who suffer from loss caused by air pollution. The beneficiaries apply the corresponding compensation to the cost of protecting the air ecological environment. Much ecological compensation in the field of air protection is practiced in China. For example, Hubei province implemented the Interim Measures for Ecological Compensation of Ambient Air Quality in 2015. From 2015 to 2018 , the annual average concentrations of major air pol- 
lutants, such as sulphur dioxide $\left(\mathrm{SO}_{2}\right)$, inhalable particulate matter $\left(\mathrm{PM}_{10}\right)$, and fine particulate matter $\left(\mathrm{PM}_{2.5}\right)$, in the region has a decreasingly yearly trend (Fig. 1). The results show the environmental air quality of Hubei Province has been improving continuously, and the effect of ecological compensation incentive mechanisms for environmental air quality is obvious.

An in-depth study on the ecological compensation mechanism for protecting air quality in Hubei Province, China should be conducted to implement better a green ecological development strategy and promote the construction of ecological civilization and sustainable economic and societal development. The main ideas, policy framework, and compensation methods of the ecological compensation mechanism should also be analysed. Further studies should be conducted to provide reference and enlightenment to improve this mechanism of protecting air quality in relevant areas.

\section{STATE OF ART}

Ecological compensation refers to the payments for ecosystem/environmental services (PES), specifically to the voluntary transaction behaviour of conditional payments made by users of environmental services to environmental service providers for providing certain natural resource services (Wunder 2015). PES is a transparent system based on the beneficiary payment principle (rather than polluter payment) and certain natural resource management rules require the environmental services traded to be clear and measurable. In recent years, PES has become an increasingly important tool for resource and environmental management. As an important endogenous incentive and constraint mechanism, PES has become the core content of cross-border environmental pollution control (Kolinjivadi et al. 2014).
Tran et al. (2016) considered the implementation of the forest environmental service project in Dabei District, Heping Province in Vietnam as an example to reveal how the PES project can help achieve the goals of the central government. The results showed that because of the incomplete design at the central level and the lack of strategic management, proving whether the project improved the level of ecosystem services and forest management is difficult. Ingram et al. (2014) analysed four cases in Guatemala, Cambodia, and Tanzania, and summarized the general experience and lessons on the use of PES to protect the biodiversity and support poverty reduction in rural areas of tropical developing countries. Grima et al. (2016) analysed 40 PES cases in Latin America and provided concepts for decision-makers to design future PES projects with a high probability of success. Leimona et al. (2015) made an empirical observation of the emerging PES mechanism in Asia by analysing case studies in Indonesia, the Philippines, and Nepal. The results showed equity and efficiency should be achieved simultaneously in the design and implementation of sustainable programs, especially in developing countries. Guo (2016) analysed the interprovincial air ecological compensation mechanism in Shandong Province from the perspectives of background, thinking, and policy framework. The author believed promoting this interprovincial air ecological compensation model is necessary for China. Shi et al. (2017) proposed the ecological compensation model for ambient air quality based on regional integration by analysing the practice of ecological compensation for ambient air quality in Shandong, Hubei, Henan, and other provinces. This model solved to some extent the dilemma caused by the fragmentation management model of a local government to the collective action. Liu (2015) proposed the implementation of the market-oriented ecological compensation model for environmental air pollution in Beijing, Tianjin, and Hebei, emphasizing the role of

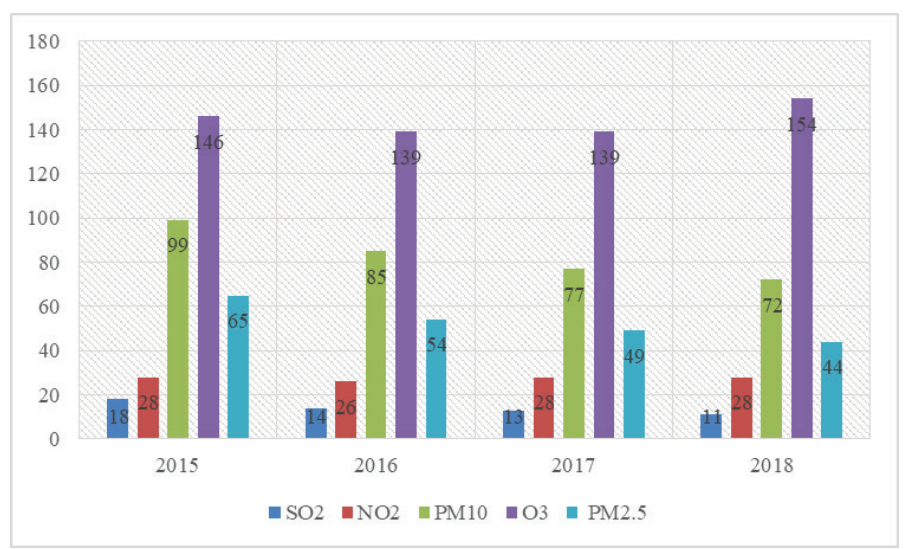

Fig. 1: Variation in the annual average concentration $\left(\mu \mathrm{g} / \mathrm{m}^{3}\right)$ of the main air pollutants in Hubei Province, China (2015-2018). 
the market in the optimal allocation of clean environmental air quality resources.

Ecological compensation can be divided into two categories. First, this process is dominated by the government, which pays for the ecological environment service through the purchase expenditure and the main purchase funds are financed by the government. The main forms of compensation include the establishment of the ecological fund, direct compensation, or transfer payment, such as the "Land Reclamation Plan" in the United States and the "Ecological Value-Added Tax" in Brazil (Yang et al. 2020). Second, the market-oriented type, that is, the introduction of market competition mechanism, is within the scope of ecological environment protection, elucidating the property rights. Thus, the protectors and consumers of the environment and resources can buy and sell in the free and open trading market, in which the quantification and standardization of the ecological environment are essential (He et al. 2019).

\section{METHODOS}

A detailed investigation of the compensation mechanism of ambient air quality in Hubei Province was performed using the method of text investigation to explore the actual scheme of ecological compensation for ambient air quality in Hubei Province of China. The investigation contents include the basic situation of compensation for ambient air quality, methods and modes of ecological compensation for ambient air quality, and the benefits of environmental quality improvement. We also heeded the opinions of experts and relevant management departments on the problems in the implementation of ecological compensation for ambient air quality. Finally, we obtained a clear understanding of the overall situation of the ecological compensation mechanism for ambient air quality in Hubei Province.

\section{RESULT ANALYSIS AND DISCUSSION}

\section{Subject of Ecological Compensation}

The pursuit of cost and income equality is the basic condition and important driving force for local governments to actively participate in the treatment of environmental air pollution. The ecological compensation system of ambient air quality is an effective way to realize the win-win scenario of economic development and environmental protection in a short period. According to the basic concept of "who pollutes, who governs, who benefits, who pays," the subject of ecological compensation for environmental air quality should be the consumer who destroys the environmental air quality. The object to be compensated should be the subject whose benefit of ambient air quality has been damaged or the actor who protects the ambient air quality and improves the ambient air quality. The object of environmental air quality protection is environmental interest. Environmental air quality pollution involves three kinds of interest subjects, namely, the government (pollution control subject), public (public interest subject), and polluter (pollution discharge subject). According to the principal-agent theory, the government collects fees from the polluters to control environmental air pollution to protect the public's "healthy breathing right." At present, the ecological compensation of ambient air quality in Hubei Province is focused mainly on charging the polluter, emphasizing the incentive and restriction to the subject of pollution control, and less on the incentive, restriction, and interest coordination to the subject of pollution control (local governments) at all levels. Therefore, the leading role of the government should give a full role in the prevention and control of environmental air pollution. To some extent, how to play a positive and active role of the government determines the performance of environmental air quality management, regardless of how the responsibility of environmental air pollution or the responsibility of environmental air quality protection is pursued. In the actual operation of ecological compensation for environmental air quality, based on a clear definition of property rights, local governments are usually mainly responsible for environmental air pollution control. These governments are supplemented by high-level governments, which constitute the regional ecological compensation mechanism.

\section{Mode of Ecological Compensation}

Ecological compensation of ambient air quality should not only determine the subject of compensation responsibility but also formulate compensation methods. In general, ecological compensation of ambient air quality includes direct and indirect compensation. Among these compensation mechanisms, direct compensation is provided mainly by the government departments to the compensated areas with certain funds or physical objects, such as government financial transfer payment, special compensation funds, and production equipment compensation, which can better save transaction costs and improve the regional ambient air quality in the short term. At present, financial transfer payment and special compensation funds are used increasingly in the ecological compensation of ambient air quality because of their advantages of special funds and institutional management. Indirect compensation is when the government gives certain financial and tax policy preferences, environmental protection technology, and scientific and technological personnel support to the compensated area. Indirect compensation emphasizes the pulling effect of the development of the green industry in 
the compensated area on the beneficiary area and reduces the financial burden of the government. Although direct and indirect compensations have their distinct advantages, the enthusiasm of direct compensation in mobilizing enterprises and the public to participate in ecological construction is limited, and the government's sufficient financial payment capacity and the limitation in the overall institutional environment should be considered. The difficulty of indirect compensation lies not only in the challenge in identifying the eco-environmental protection industry but also in the prevention of the regional ecological deprivation caused by the transfer of pollution industries. The ecological compensation of ambient air quality not only needs to improve the ambient air quality in the short term but also a long-term regional sustainable development model. Therefore, the dual role of direct and indirect compensations should be strengthened to better promote the improvement of ambient air quality. The majority of the ecological compensation methods for ambient air quality in Hubei Province involves direct compensation. Hence, indirect compensation methods should be further optimized to promote the continuous improvement of ambient air quality.

The policy framework of the air ecological compensation mechanism in Hubei Province is shown in Fig. 2. The framework mainly includes the withholding and compensation system of an air ecological compensation fund, an innovative air monitoring management system, and improved performance assessment. Among these parameters, the withholding and compensation system of air ecological compensation fund is the core content, which not only stipulates the way of withholding and compensation but also specifies the scope of use of funds. These processes further strengthen the legal responsibility and obligation of local governments to protect air ecology.

Using the withholding and compensation system of an air ecological compensation fund, Hubei Province has detected accurately the changes in the various pollutant concentrations in the air of each city. The Environmental Protection Depart- ment calculated the amount to be withheld and compensated every quarter. For cities with deteriorating air quality, the provincial Environmental Protection Leading Group reports the withholding amount to the Provincial Department of Finance. The Provincial Department of Finance then withholds directly from the city's financial account and issues a written notice of withholding to the city. For cities with improved air quality, the Provincial Department of Finance issues compensation to the municipal finance and publishes the withholding and compensation amount and ranking of each city in the brief on Hubei's environmental protection and the official website of the Hubei Environmental Protection Department. Following the practice of the provincial government, cities at all levels have formulated a withholding and compensation system of air ecological compensation in each region, but knowing how the compensation standard is determined is the key to implement air ecological compensation. Given the regional differences, the year-on-year changes of ambient air quality of each place can be considered reasonably as the starting point for the calculation.

\section{Standard of Ecological Compensation}

At present, three main methods are used in determining the payment standard of ecological compensation. The first method is based on the cost assessment method, including the opportunity cost method and the conservation cost method. The second technique is based on the income evaluation method, including the ecosystem services value method and the market value method. The third method is based on the payment ability evaluation method, which includes the contingent valuation method and the payment ability method (Wei et al. 2019).

The standard of ecological compensation is the key and most difficult point of establishing an ecological compensation mechanism. However, when implementing compensation, distinguishing between the natural value of ambient air quality and added value of ecological construction is difficult. In practice, the most widely used method is the

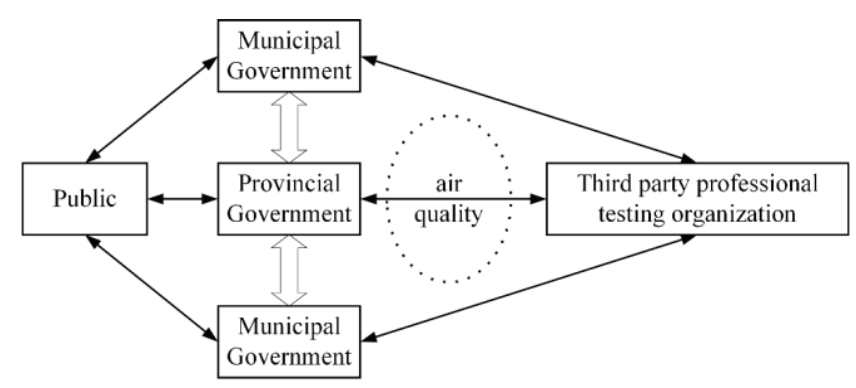

Fig. 2: Policy framework of air ecological compensation mechanism in Hubei Province. 
willingness negotiation method between the payer and the compensated party. This method can be used in designing the ecological compensation standard of ambient air quality through the willingness of the payer and the payee. In the actual operation, the game between the payer and the compensation party often leads difficulties in determining the compensation standard. Thus, this method requires high-level coordination agencies to play a positive role in promotion and adjudication. In selecting the true and accurate cost accounting indicators and methods, the ecological value of ambient air quality and the enthusiasm of local governments to improve ambient air quality and the government's financial expenditure capacity should all be considered. Fair and effective compensation standards should also be established.

The assessment indicators of ecological compensation for ambient air quality are $\mathrm{PM}_{10}$ and $\mathrm{PM}_{2.5} . \mathrm{PM}_{10}$ and $\mathrm{PM}_{2.5}$ are assessed by the city (prefecture). $\mathrm{PM}_{10}$ and $\mathrm{PM}_{2.5}$ of counties (districts) were assessed from 2017. The assessment data adopt the automatic monitoring data of ambient air quality confirmed by an audit. The ecological compensation fund for ambient air quality is calculated according to Equations (1) $-(3)$.

Calculation of ecological compensation fund for city (prefecture) ambient air quality:

$$
\begin{gathered}
M_{1}=\left(A_{\text {last year }}-A_{\text {this year }}\right) \times m_{1} \times k+ \\
\left(B_{\text {last year }}-B_{\text {this year }}\right) \times m_{1} \times k .
\end{gathered}
$$

Calculation of ecological compensation fund for county (district) ambient air quality:

Calculation method in 2017:

$$
M_{2}=\left(A_{\text {last year }}-A_{\text {this year }}\right) \times m_{2} \times k .
$$

Calculation method in 2018 and later:

$$
\begin{gathered}
M_{2}=\left(A_{\text {last year }}-A_{\text {this year }}\right) \times m_{2} \times k+ \\
\left(B_{\text {last year }}-B_{\text {this year }}\right) \times m_{2} \times k,
\end{gathered}
$$

Where,

$M_{1}$ and $\mathrm{M}_{2}$ are ecological compensation funds for ambient air quality (unit: ten thousand RMB);

$m_{1}$ and $m_{2}$ are the ecological compensation fund coefficients of ambient air quality [unit: ten thousand $\mathrm{RMB} /(\mu \mathrm{g} /$ $\left.\mathrm{m}^{3}\right)$;

$A_{\text {last year }}$ represents the average concentration of $\mathrm{PM}_{10}$ in the previous year (unit: $\mu \mathrm{g} / \mathrm{m}^{3}$ );

$A_{\text {this year }}$ refers to the average concentration of $\mathrm{PM}_{10}$ in the present year (unit: $\mu \mathrm{g} / \mathrm{m}^{3}$ );

$B_{\text {last year }}$ represents the average concentration of $\mathrm{PM}_{2.5}$ in the previous year (unit: $\mu \mathrm{g} / \mathrm{m}^{3}$ );
$B_{\text {this year }}$ is the average concentration of $\mathrm{PM}_{2.5}$ in the present year (unit: $\mu \mathrm{g} / \mathrm{m}^{3}$ ); and

$k$ is the weather change coefficient, with a value between $0.5-1$.

If the annual average concentrations of $\mathrm{PM}_{10}$ and $\mathrm{PM}_{2.5}$ reach the secondary standard of the Ambient Air Quality Standard (GB3095-2012) for two consecutive years, the capital coefficient $m_{1}$ of the city (prefecture) is 80 and the capital coefficient $m_{2}$ of the county (district) is 40 .

If the annual average concentrations of $\mathrm{PM}_{10}$ and $\mathrm{PM}_{2.5}$ meet the secondary standard of the Ambient Air Quality Standard (GB3095-2012), the calculation result is negative according to the above method. The ecological compensation fund for ambient air quality will not be withheld. If the annual average concentrations of $\mathrm{PM}_{10}$ and $\mathrm{PM}_{2.5}$ fail to meet the secondary standard of the Ambient Air Quality Standard (GB3095-2012), the calculation result is positive following the above method, but the assessment index fails to meet the annual goal. Thus, the ecological compensation fund for ambient air quality will not be awarded and will be implemented from 2019.

\section{CONCLUSION}

An ecological compensation system of environmental air quality that can address serious environmental air quality problems should be established with the government as the leading force and the fiscal policy of allocating public resources as the main tool. This system can enhance the enthusiasm of the region to maintain the ecological environment. Based on the regional integration of the environmental air quality ecological compensation system in Hubei Province of China, the basic starting point is to solve the problems in the regional environmental air quality, focusing on promoting the solution of the external problems of environmental air pollution. According to the characteristics of publicity, mobility, and externality of environmental air pollution, a fair and reasonable responsibility-sharing, and regional unified planning and accountability should be established to truly improve the ecological compensation system to protect the environmental air quality.

\section{REFERENCES}

Grima, N., Singh, S.J., Smetschka, B. and Ringhofer, L. 2016. Payment for ecosystem services (PES) in Latin America: Analysing the performance of 40 case studies. Ecosystem Services, 17: 24-32.

Guo, G. J. 2016. Research on intergovernmental air ecological compensation mechanism in context of cross-border governance in air pollution: Based on case of Shandong province's intergovernmental air ecological compensation practice. Resource Development \& Market, 32(7): 832-837.

He, J., Wan, Y., Tang, Z., Zhu, X. and Wen, C. 2019. A developed framework for the multi-district ecological compensation standards integrating 
ecosystem service zoning in an urban area in China. Sustainability, 11(18): 4876.

Ingram, J. C., Wilkie, D., Clements, T., McNab, R.B., Nelson, F., Baur, E.H., Sachedinae, H.T., Peterson, D.D. and Foley, C.A.H. 2014. Evidence of payments for ecosystem services as a mechanism for supporting biodiversity conservation and rural livelihoods. Ecosystem Services, 7: 10-21.

Kolinjivadi, V., Adamowski, J. and Kosoy, N. 2014. Recasting payments for ecosystem services (PES) in water resource management: A novel institutional approach. Ecosystem Services, 10: 144-154.

Leimona, B., Van Noordwijk, M., De Groot, R. and Leemans, R. 2015. Fairly efficient, efficiently fair: Lessons from designing and testing payment schemes for ecosystem services in Asia. Ecosystem Services, 12: 16-28.

Liu, W. 2015. Establishment of market-oriented ecological compensation model for air pollution in Beijing-Tianjin-Hebei. Modernization of Management, 35(2): 64-65.

Mao, B., Ao, C., Wang, J., Sun, B. and Xu, L. 2020. Does regret matter in public choices for air quality improvement policies? A comparison of regret-based and utility-based discrete choice modelling. Journal of Cleaner Production, 120052.
Shi, H. J. and Guang, X. 2017. Study on the Ecological Compensation System of the Atmospheric environment Based on the Regional Integration. Environment and Sustainable Development, 42(3): 27-30.

Tran, T.T.H., Zeller, M. and Suhardiman, D. 2016. Payments for ecosystem services in Hoa Binh province, Vietnam: An institutional analysis. Ecosystem Services, 22: 83-93.

Wang, W.Q. 2014. Cross regional cooperative treatment of air pollution: Taking Beijing as an example. Journal of Public Management, 1: 60-69.

Wei, W.X. and Wang, Y. H. 2019. A study on the payment standards for environmental services in air pollution governance of Beijing-Tianjin-Hebei. Journal of Finance and Economics, 45(4): 96-110.

Wunder, S. 2015. Revisiting the concept of payments for environmental services. Ecological Economics, 117: 234-243.

Yang, Y., Yao, C. and Xu, D. 2020. Ecological compensation standards of national scenic spots in western China: A case study of Taibai Mountain. Tourism Management, 76: 103950.

Yu, B., Xu, L. and Yang, Z. 2016. Ecological compensation for inundated habitats in hydropower developments based on carbon stock balance. Journal of Cleaner Production, 114: 334-342. 